\title{
TYPING CANDIDA ALBICANS ORAL ISOLATES FROM HEALTHY BRAZILIAN SCHOOLCHILDREN USING MULTILOCUS ENZYME ELECTROPHORESIS REVEALS TWO HIGHLY POLYMORPHIC TAXA
}

Marcelo Fabiano Gomes Boriollo ${ }^{1}$, Denise Madalena Palomari Spolidorio ${ }^{2}$, Letizia Monteiro Barros ${ }^{1}$, Rodrigo Carlos Bassi $^{1}$, José Antonio Dias Garcia ${ }^{1}$, Ana Maria Duarte Dias Costa ${ }^{1}$, Edvaldo Antonio Ribeiro Rosa ${ }^{3}$, José Francisco Höfling ${ }^{4}$

${ }^{1}$ Laboratório de Genética e Biologia Molecular, Faculdade de Ciências Médicas, Universidade de Alfenas, Alfenas, MG, Brasil;

${ }^{2}$ Laboratório de Microbiologia Oral e Imunologia, Departamento de Patologia and Fisiologia Oral, Faculdade de Odontologia, Universidade Estadual Paulista, Araraquara, SP, Brasil; ${ }^{3}$ Laboratório de Microbiologia Oral, Centro de Ciências Biológicas e da Saúde, Pontificia Universidade Católica do Paraná, Curitiba, PR, Brasil; ${ }^{4}$ Laboratório de Microbiologia Oral e Imunologia, Faculdade de Odontologia, Universidade Estadual de Campinas, Piracicaba, SP, Brasil.

Submitted: June 04, 2010; Returned to authors for corrections: October 13, 2010; Approved: March 14, 2011.

\begin{abstract}
The genetic diversity of $C$. albicans oral isolates from 75 healthy schoolchildren from eight schools located in different geographic areas of Piracicaba city, São Paulo state, Brazil, was established using isoenzymes marker (Multilocus Enzyme Electrophoresis - MLEE) and cluster analysis. Patterns of monoclonal and polyclonal oral colonization by $C$. albicans within and between groups of schoolchildren were identified. However, significant divergence between the observed and the expected genotypic frequencies (HardyWeinberg equilibrium test) was not detected in the geographically adjacent groups, suggesting the hypothesis that populations of healthy schoolchildren do not correspond to the selection factor (differential survival) of strains. Two highly polymorphic and distantly genetically related taxa (A and B) were identified within the total population of yeasts, each contained subgroups (A1, A2, A3, A4, B1 and B2) and clusters of moderately related strains (from I to X), suggesting the existence of strains restricted or not to certain groups of geographically limited, healthy students. However, the coexistence of identical strains in healthy schoolchildren from the same school (geographically related) reinforces the hypothesis of oral transmission, where the sources of propagation could be explored. Furthermore, this could also be used in current and retrospective analyses of $C$. albicans isolated from immunocompetent and immunocompromised people, in order to detect commensal or potentially pathogenic yeast groups, predominantly in candidiasis, and in the development of strategies to prevent transmission or human propagation.
\end{abstract}

Key words: Candida albicans, healthy schoolchildren, geographic region, MLEE, cluster analysis.

\footnotetext{
*Corresponding Author. Mailing address: Laboratory of Molecular Biology and Genetics, Medical Sciences School, University of Alfenas, Rod. MG 179, Km 0 - Universitary Campus, CEP 37130-000, Alfenas, MG, Brazil.; Tel.: +55 35 3299-3255.; E-mail: marcelo.boriollo@ unifenas.br
} 


\section{INTRODUCTION}

Candida albicans (Ascomycota; Saccharomycetales) and related species are opportunistic pathogens that cause infections ranging from simple mucocutaneous disorders to invasive diseases involving multiple organs. The frequency of such infections has increased worldwide as the result of a multiplicity of predisposing factors which include procedures that disrupt the integrity of the mucocutaneous barrier, qualitative and quantitative neutrophil dysfunction, old age, and metabolic disorders such as, diabetes mellitus, impaired salivary gland function, antibiotic therapy, the use of dentures, carbohydrate-rich diets, smoking, Cushing syndrome, immunosuppressive conditions such as human immunodeficiency virus (HIV) infection, malignancies, and nutritional deficiencies. Therefore, conditions such as Sjögren syndrome, radiotherapy of the head and neck, or drugs that reduce salivary secretions could lead to an increased risk of oral candidosis $(1,39,50-52)$. Candida species can be found commensally in the microbiota of human cavities (rectal, oral, vaginal, urethral, nasal, and aural) and on skin (60). Their presence in the microbiota of healthy people remains unexplained. However, nutritional factors, interactions with bacterial microbiota, and the presence of salivary antibodies have been suggested as influences in the incidence of these yeasts (69). The presence of Candida species in the oral cavities of healthy schoolchildren living in Piracicaba city, São Paulo state, Brazil, showed certain equivalence between groups of children and a prevalence of $47.3 \%$ (i.e., 113 Brazilian children showed the presence of Candida spp.), however without any correlation to salivary secretion rate, salivary buffer capacity, Candida spp. CFU/mL, caries risk and socioeconomic categories. Candida albicans only was most commonly isolated following by $C$. albicans association to $C$. tropicalis, C. krusei and C. parapsilosis (33). The detection of yeasts in the mouth of healthy individuals can also oscillate depending on collection technique, age and race of the subject, and methodology utilized to quantify and qualify the hostparasite interaction (64).

The interest in acquiring a better understanding of the pathogenesis and epidemiology of infections caused by $C$. albicans has led to numerous studies which have employed molecular methods such as RAPD, REA, Ca3 fingerprinting and electrophoretic karyotyping $(15,23,30,32$, 40, 42, 49, 5559, 65, 74). Multilocus Enzyme Electrophoresis (MLEE) has been considered the gold standard method for population genetics in microorganisms (7), with high discriminatory power and reproducibility $(7,9,11,34,42,66)$. Its electrophoretic patterns are often predictable, since they depend on the genetic and nuclear conditions of each organism. In this context, different interpretation criteria were used for haploid or diploid organisms $(11,21,34,63)$. Based on these criteria, the allelic composition has been determined from a group consisting of ten to thirty metabolic enzymes, considered representative of the total genome (7). The results obtained by MLEE have been used for a variety of purposes in the field of medical microbiology. In terms of specific alleles, the allelic proportions have inferred the degree of genetic recombination in natural populations. These proportions have also been used to evaluate the degree of genetic isolation between natural populations, caused by geographic, ecological or biological barriers. Its use has demonstrated systematic and taxonomic relevance since, for clonal microorganisms, the degree of interand intra-population relationships have been analyzed. Speciesspecific clones identified by MLEE have also been associated with clinical patterns and relapses, and high indices of pathogenicity. Finally, these results have been used in epidemiological studies that allow a better understanding of the development of epidemics, which represents an invaluable addition to molecular typing methods today, particularly in epidemiological studies on a large scale (7). In the field of medical mycology, MLEE has shown great potential in studies of taxonomic, systematic, genetic, evolutionary and epidemiological characterization, especially for the yeast $C$. 
albicans (3-5, 8-11, 13, 42-44, 47).

Using isoenzyme markers and cluster analyses, this study evaluated the genetic relationship and distribution of $C$. albicans strains previously isolated from the oral cavities of healthy schoolchildren, from 8 schools located in different geographic areas (central and peripheral areas) of Piracicaba city, São Paulo state, Brazil. The important question regarding the transmission and propagation of oral microbial strains among healthy schoolchildren, and possibly between the latter and immunocompromised individuals, who temporarily occupy to the same area has been discussed and this provides the impetus to develop strategies for preventing infections and maintaining hygiene and oral health.

\section{MATERIALS AND METHODS}

\section{Yeasts}

The study involved seventy-five $C$. albicans samples isolated from oral cavities of schoolchildren chosen randomly, varying between six and nine years old, of both genders, from eight schools located in different geographic areas of Piracicaba city, São Paulo state, Brazil: forty three schoolchildren from five schools in central area and thirty two schoolchildren from three schools in peripheral area (Table 1). These samples were identified previously by germ tube test, chlamydospore test, growth in chromogenic medium CHROMagar Candida ${ }^{\circledR}$, carbohydrate assimilation and fermentation tests (33), kindly provided by the group of researchers from the Laboratory of Oral Microbiology and Immunology, Piracicaba Dental School, State University of Campinas.

\section{Multilocus Enzyme Electrophoresis (MLEE)}

Yeast cultures and enzyme extraction procedures were accomplished according to methodologies previously described $(10,11)$. Enzymes were separated in $13 \%$ starch gels (Penetrose $30^{\circledR}$; Refinações de Milho Brasil Ltda) by horizontal and continuous electrophoretic systems, at $130 \mathrm{~V}$ at $4{ }^{\circ} \mathrm{C}$ overnight. The enzymes of each $C$. albicans sample were evaluated at least thrice on different gels and electrophoretic runs. In addition, the $C$. albicans CBS 562 enzymes (Centraalbureau voor Schimmelcultures, Delft, the Netherlands) were included in study to ensure reproducible results. The enzymatic activities were determined by methods previously described for 11 enzymes (15 enzyme loci) (Table 2) (2, 10, 11). Pattern interpretation was performed following the general rules commonly accepted in the deduction of the allelic composition and of the genotype of diploid organisms. Subtypes or strains (i.e., electrophoretic type [ET]), the polymorphic loci percentage (frequency of the most common allele $<0.99$ ), the average number of alleles per locus, the average number of alleles per polymorphic locus, and the number of alleles between heterozygotes and homozygotes, were also established (2, $11,22,38,63$ ). The frequency of alleles/genotypes (equilibrium test of Hardy-Weinberg) was calculated for each enzyme locus $(13,22)$. Heterozygotes were determined by the equation $h=1-\sum_{i}$ $\left(p_{i}^{2}\right), p_{i}$ being the average frequency of the allele $i$ in the population (37).

Table 1. Distribution of 75 schoolchildren, varying between six and nine years old, of both genders, in eight schools located in different geographic areas (central and peripheral) of Piracicaba city, São Paulo state, Brazil.

\begin{tabular}{lc}
\hline Schools (code) & Number of schoolchildren \\
\hline Central Area & 6 \\
Colégio Alphaville (A) & 10 \\
Escola Estadual de Primeiro Grau "Profa. Francisca Elisa" (B) & 10 \\
Escola Estadual de Primeiro e Segundo Grau "Prof. Honorato Faustino" (C) & 11 \\
Liceu Colégio Albert Einstein (D) & 6 \\
Escola Estadual de Primeiro e Segundo Grau "Prof. Manasses Ephraim Pereira" (E) & \\
Peripheral Area & 9 \\
Escola Estadual de Primeiro Grau "Prof. Carlos Sodero" (F) & 16 \\
Escola Estadual de Primeiro Grau "Prof. Francisco Mariano da Costa" (G) & 7 \\
Escola Estadual de Primeiro e Segundo Grau "Prof. Elias de Melo Ayres" (H) & \\
\hline
\end{tabular}


Table 2. Systems and solutions utilized for MLEE analysis from metabolic enzymes of $C$. albicans.

\begin{tabular}{|c|c|c|c|c|c|c|c|}
\hline $\begin{array}{c}\text { Enzyme } \\
\text { EC (Enzyme } \\
\text { Commission) } \\
\text { number }\end{array}$ & Name & Symbol & $\begin{array}{c}\text { Compound for staining } \\
\text { Substrate }\end{array}$ & Buffer & Salt & Coenzyme & Dye catalyser \\
\hline 1.1.1.1. & Alcohol dehydrogenase & $\mathrm{ADH}$ & Ethanol (3 mL) Isopropanol ( $2 \mathrm{~mL})$ & $200 \mathrm{mM}$ Tris- $\mathrm{HCl} \mathrm{pH} 8.0 \quad(50 \mathrm{~mL})^{\mathrm{a}}$ & & NAD $1 \%(2 \mathrm{~mL})$ & $\begin{array}{l}\text { PMS } 1 \%(500 \mu \mathrm{L}) \\
\text { MTT } 1.25 \%(1 \mathrm{~mL})\end{array}$ \\
\hline 1.1.1.14. & Sorbitol dehydrogenase & $\mathrm{SDH}$ & Sorbitol (250 mg) & Tris-HCl $50 \mathrm{mM}$ pH $8.0 \quad(50 \mathrm{~mL})^{\mathrm{b}}$ & & NAD 1\% (2 mL) & $\begin{array}{l}\text { PMS } 1 \%(500 \mu \mathrm{L}) \\
\text { MTT } 1.25 \%(1 \mathrm{~mL})\end{array}$ \\
\hline 1.1.1.17. & $\begin{array}{l}\text { Mannitol-1-phosphate } \\
\text { dehydrogenase }\end{array}$ & M1P & Mannitol-1-phosphate $\quad(5 \mathrm{mg})$ & Tris-HCl $100 \mathrm{mM} \mathrm{pH} 8.5(50 \mathrm{~mL})^{\mathrm{c}}$ & & NAD $1 \%(2 \mathrm{~mL})$ & $\begin{array}{l}\text { PMS } 1 \%(500 \mu \mathrm{L}) \\
\text { MTT } 1.25 \%(1 \mathrm{~mL})\end{array}$ \\
\hline 1.1.1.37. & Malate dehydrogenase & $\mathrm{MDH}$ & $2 \mathrm{M}$ Malic acid $(6 \mathrm{~mL})^{\mathrm{d}}$ & Tris-HCl $200 \mathrm{mM} \mathrm{pH} 8.0 \quad(40 \mathrm{~mL})^{\mathrm{a}}$ & & NAD 1\% (2 mL) & $\begin{array}{l}\text { PMS } 1 \%(500 \mu \mathrm{L}) \\
\text { MTT } 1.25 \%(1 \mathrm{~mL})\end{array}$ \\
\hline 1.1.1.42. & Isocitrate dehydrogenase & IDH & $1 \mathrm{M}$ Isocitric acid $(2 \mathrm{~mL})^{\mathrm{e}}$ & Tris-HCl $200 \mathrm{mM}$ pH $8.0(40 \mathrm{~mL})^{\mathrm{a}}$ & $\begin{array}{l}100 \mathrm{mM} \mathrm{MgCl} \\
(1 \mathrm{~mL})^{\mathrm{f}}\end{array}$ & NADP $1 \%(1 \mathrm{~mL})$ & $\begin{array}{l}\text { PMS } 1 \%(500 \mu \mathrm{L}) \\
\text { MTT } 1.25 \%(1 \mathrm{~mL})\end{array}$ \\
\hline 1.1.1.47. & Glucose dehydrogenase & GDH & D-glucose (500 mg) & Tris-HCl $200 \mathrm{mM}$ pH $8.0(50 \mathrm{~mL})^{\mathrm{a}}$ & & NAD $1 \%(2 \mathrm{~mL})$ & $\begin{array}{l}\text { PMS } 1 \%(500 \mu \mathrm{L}) \\
\text { MTT } 1.25 \%(1 \mathrm{~mL})\end{array}$ \\
\hline 1.1.1.49. & $\begin{array}{l}\text { Glucose-6-phosphate } \\
\text { dehydrogenase }\end{array}$ & G6PDH & $\begin{array}{l}\text { Glucose-6-phosphate disodium salt } \\
\text { (100 mg) }\end{array}$ & Tris-HCl $200 \mathrm{mM} \mathrm{pH} 8.0(50 \mathrm{~mL})^{\mathrm{a}}$ & $\begin{array}{l}100 \mathrm{mM} \mathrm{MgCl} \\
(1 \mathrm{~mL})^{\mathrm{f}}\end{array}$ & NADP $1 \%(1 \mathrm{~mL})$ & $\begin{array}{l}\text { PMS } 1 \%(500 \mu \mathrm{L}) \\
\text { MTT } 1.25 \%(1 \mathrm{~mL})\end{array}$ \\
\hline 1.4.3.x. & Aspartate dehydrogenase & ASD & Aspartic acid (50 mg) & Sodium phosphate $\mathrm{pH} 7.0(50 \mathrm{~mL})^{\mathrm{g}}$ & & NAD 1\% (2 mL) & $\begin{array}{l}\text { PMS } 1 \%(500 \mu \mathrm{L}) \\
\text { MTT } 1.25 \%(1 \mathrm{~mL})\end{array}$ \\
\hline 1.11.1.6. & Catalase $^{\mathrm{h}}$ & CAT & & & & & \\
\hline 1.11.1.7. & Peroxidase & $\mathrm{PO}$ & $\mathrm{H}_{2} \mathrm{O}_{2} 3 \%(1 \mathrm{~mL})$ & $100 \mathrm{mM}$ Sodium acetate $\mathrm{pH} 4.5(50 \mathrm{~mL})^{\mathrm{i}}$ & & & $\begin{array}{l}\text { o-dianisidine } 2 \mathrm{HCl} \\
(16 \mathrm{mg})\end{array}$ \\
\hline 3.4.11.1. & Leucine aminopeptidase & LAP & $\begin{array}{l}\text { L-leucine } \beta \text {-naphthylamide } \mathrm{HCl} \\
\text { (30 mg) }\end{array}$ & $\begin{array}{l}100 \mathrm{mM} \text { Potassium phosphate } \mathrm{pH} 5.5(50 \\
\mathrm{mL})^{\mathrm{j}}\end{array}$ & $\begin{array}{l}100 \mathrm{mM} \mathrm{MgCl} \\
(1 \mathrm{~mL})^{\mathrm{f}}\end{array}$ & & Black K (30 mg) \\
\hline
\end{tabular}




\section{Cluster analysis}

Nei's distance (1972) was used to estimate the genetic distance among the isolates of $C$. albicans $(2,11,36,63)$. Dendrogram was generated using the SAHN grouping method (Sequential, Agglomerative, Hierarchic, Nonoverlapping Clustering Methods) and UPGMA algorithm (Unweighted Pair-Group Method Using an Arithmetic Average) (65). Since MLEE provide all levels of relatedness that must be resolved by DNA fingerprinting methods (i.e., identify the same strain in independent isolates, identify microevolutionary changes in a strain, identify clusters of moderately related isolates, and identify completely unrelated isolates), an average threshold value $\left(\bar{d}_{i j}\right)$ was established in the dendrograms in order to identify taxa (singular taxon, i.e., taxonomic group of any nature or rank) $(11,42,65,67)$. The Pearson product-moment correlation coefficient was used as a measure of the agreement between the genetic distance values implied by the UPGMA dendrogram (i.e., correlation matrix derived from UPGMA dendrogram $-C_{j k}$ ) and that of the original genetic distance matrix $\left(d_{i j}\right)$. Such agreement was interpreted as follows: $r_{j k} \geq$ 0.9 as very good fit, $0.8 \leq r_{j k}<0.9$ as good fit, $0.7 \leq r_{j k}<0.8$ as poor fit, and $r_{j k}<0.7$ as very poor fit. All of these analyses were carried out using the program NTSYS-pc $2.1(11,46,65)$.

\section{RESULTS}

\section{Genetic interpretation of the MLEE patterns}

The genetic interpretation of MLEE patterns allowed the identification of strains (Electrophoretic Types - ETs) and it showed intrinsic genetic characteristics for each $C$. albicans population (Table 3). Quantitative and/or qualitative variations of the polymorphic loci, of the average number of alleles per locus, of the average number of alleles per polymorphic locus, and of the heterozygosity were observed in all $C$. albicans populations isolated from oral cavities of healthy schoolchildren (Table 4). No significant divergence between observed and expected genotypic frequencies was observed in the $C$. albicans populations - Hardy-Weinberg equilibrium test (data not shown). In addition, the determination of $C$. albicans strains (electrophoretic types - ETs) by the MLEE method and genetic interpretation revealed monoclonal and polyclonal patterns of oral colonization between healthy schoolchildren from eight schools located in different geographic areas (central or peripheral) of Piracicaba city, São Paulo state, Brazil. Polyclonal patterns of $C$. albicans were observed within and among all populations of healthy schoolchildren (A, B, C, D, E, F, G, and H) geographically unrelated from central and peripheral areas. Monoclonal patterns of $C$. albicans were observed within the populations; B (4 of 10 schoolchildren/isolates - ET24 and ET32), C (3 of 10 schoolchildren/isolates - $\begin{array}{lllll}\text { ET32), } & \text { E } \quad(2) \text { of } 6\end{array}$ schoolchildren/isolates $\quad-\quad$ ET10), $\quad$ F $\quad(4$ of 9 schoolchildren/isolates - ET23 and ET24), G (6 of 16 schoolchildren/isolates - ET23, ET24 and ET28), and H (2 of 7 schoolchildren/isolates - ET32), and between the populations; A and D (central area - ET1); H and G (peripheral area - ET4); $\mathrm{B}$ and $\mathrm{H}$ (central and peripheral areas - ET9); A, B and E (central area - ET10); D, F, G and H (central and peripheral areas - ET23); B, F and G (central and peripheral areas ET24); F and G (peripheral area - ET28); A and E (central area - ET31); A, B, C, E, G and H (central and peripheral areas ET32); C, D and H (central and peripheral areas - ET33); C and G (central and peripheral areas - ET34); A and D (central area - ET37).

\section{Cluster analysis}

The genetic diversity of oral isolates of C. albicans from 75 healthy schoolchildren from eight schools located in different geographic areas (central or peripheral) of Piracicaba city, São Paulo state, Brazil, was analyzed using Nei's distance (45) and UPGMA dendrogram (Fig. 1). The genetic diversity of the total yeast population ranged from 0 to 0.148 , that is, on average, the population of isolates contained from 0 to 14.8 allelic substitutions for each 100 loci, starting from a common ancestor $\left(d_{i j}=0.012 \pm 0.026\right)$. Taking into consideration the average 
genetic distance $\left(d_{i j}=0.012\right)$ obtained from the total population of yeast, these analyses also permitted the verification of the coexistence (threshold: $0.012>d_{i j} \geq 0$ - identical or highly related isolates/strains) or non-coexistence (thresholds: $0.038>$ $d_{i j} \geq 0.012$ - moderately related isolates/strains; $d_{i j} \geq 0.038-$ unrelated isolates/strains) of strains between the healthy schoolchildren and the inference of possible oral transmission between them or microevolutionary alterations. Two large highly polymorphic taxa (A and B) were identified from the $d_{i j}$ value of 0.148 . Then, genetically unrelated strains or subgroups $\left(d_{i j} \geq 0.038\right)$ were identified within each of these two large taxa which were designated A1, A2, A3, A4, B1 and B2.

Subgroup A2 comprised the greater number of clusters [Clusters II, III (this included the type strain CBS-562), IV, V, VI and VII] and moderately related strains (55.8\% of the ETs or $68 \%$ of the isolates) $\left(0.038>d_{i j} \geq 0.012\right)$ featuring (i) the coexistence of strains $\left(0.012>d_{i j} \geq 0\right)$ in healthy schoolchildren geographically related and/or unrelated (Clusters of II to VII), (ii) the exclusive existence of strains (ET2, ET7, ET19 and ET30) in some schoolchildren geographically related and unrelated $\left(\mathrm{A}_{n=1}, \mathrm{D}_{n=1}\right.$ and $\left.\mathrm{G}_{n=2}\right)$ (Fig.1), (iii) the exclusive existence of strains in the central area (Cluster VI) or the peripheral area (Clusters V and VII), and (iv) the coexistence of strains in both central and peripheral areas (Clusters II, III and IV) (Table 5):

Cluster II: 6 strains (ET6, ET23, ET24, ET26, ET27 and ET28) isolated from oral cavities of 18 healthy schoolchildren geographically related and unrelated $\left(\mathrm{B}_{n=4}, \mathrm{D}_{n=2}, \mathrm{~F}_{n=5}, \mathrm{G}_{n=6}\right.$ and $\mathrm{H}_{n=1}$ ) from the central and peripheral areas.

Cluster III: 4 strains (ET9, ET10, ET31 and ET32, included CBS-562) isolated from oral cavities of 18 healthy schoolchildren geographically related and unrelated $\left(\mathrm{A}_{n=3}, \mathrm{~B}_{n=4}\right.$, $\mathrm{C}_{n=3}, \mathrm{E}_{n=4}, \mathrm{G}_{n=1}$ and $\mathrm{H}_{n=3}$ ) from the central and peripheral areas.

Cluster IV: 3 strains (ET35, ET36 and ET42) isolated from oral cavities of 3 healthy schoolchildren geographically related and unrelated $\left(\mathrm{C}_{n=1}\right.$ and $\left.\mathrm{G}_{n=2}\right)$ from the central and peripheral areas.

Cluster V: 2 strains (ET5 and ET8) isolated from oral cavities of 2 healthy schoolchildren geographically unrelated $\left(\mathrm{F}_{n=1}\right.$ and $\left.\mathrm{G}_{n=1}\right)$ from the peripheral area.

Cluster VI: 3 strains (ET22, ET21 and ET20) isolated from oral cavities of 3 healthy schoolchildren geographically unrelated $\left(\mathrm{B}_{n=1}, \mathrm{C}_{n=1}\right.$ and $\left.\mathrm{E}_{n=1}\right)$ from the central area.

Cluster VII: 2 strains (ET3 and ET4) isolated from oral cavities of 3 healthy schoolchildren geographically related and unrelated $\left(\mathrm{G}_{n=2}\right.$ and $\left.\mathrm{H}_{n=1}\right)$ from the peripheral area.

Subgroup B2 comprised the second greater number of clusters and strains $(30.2 \%$ of the ETs or $22.7 \%$ of the isolates) featuring (i) the coexistence of strains $\left(0.012>d_{i j} \geq 0\right)$ in healthy schoolchildren geographically related and/or unrelated, (ii) the exclusive existence of strains (ET12, ET15, ET18 and ET38) in some schoolchildren geographically unrelated $\left(\mathrm{C}_{n=1}, \mathrm{D}_{n=1}, \mathrm{~F}_{n=1}\right.$ and $\mathrm{H}_{n=1}$ ) (Fig.1), (iii) the exclusive existence of strains in central area (Cluster X), and (iv) the coexistence of strains in both central and peripheral areas (Clusters VIII and IX) (Table 5):

Cluster VIII: 3 strains (ET25, ET33 and ET34) isolated from oral cavities of 6 healthy schoolchildren geographically related and unrelated $\left(\mathrm{C}_{n=2}, \mathrm{D}_{n=1}, \mathrm{~F}_{n=1}, \mathrm{G}_{n=1}\right.$ and $\left.\mathrm{H}_{n=1}\right)$ from the central and peripheral areas.

Cluster IX: 3 strains (ET11, ET13 and ET14) isolated from oral cavities of 3 healthy schoolchildren geographically unrelated $\left(\mathrm{B}_{n=1}, \mathrm{E}_{n=1}\right.$ and $\left.\mathrm{G}_{n=1}\right)$ from the central and peripheral areas.

Cluster X: 3 strains (ET37, ET39 and ET40) isolated from oral cavities of 4 healthy schoolchildren geographically related and unrelated $\left(\mathrm{A}_{n=1}, \mathrm{C}_{n=2}\right.$ and $\left.\mathrm{D}_{n=1}\right)$ from the central area.

Subgroup A1 comprised the smaller number of clusters and strains (7\% of the ETs or $5.3 \%$ of the isolates) featuring (i) the coexistence of strains $\left(0.012>d_{i j} \geq 0\right)$ in healthy schoolchildren geographically unrelated, (ii) the exclusive existence of strains (ET16 and ET17) in some healthy schoolchildren geographically related $\left(\mathrm{D}_{n=2}\right)$ (Fig.1), and (iii) the exclusive existence of strains 
in the central area (Cluster I) (Table 5):

Cluster I: 1 strain (ET1) isolated from oral cavities of 2 healthy schoolchildren geographically unrelated $\left(\mathrm{A}_{n=1}\right.$ and $\mathrm{D}_{n=}$ 1) from the central area.

Subgroups A3, A4 and B1 comprised only one strain or isolate each (7\% of the ETs or $4 \%$ of the isolates) featuring (i) the exclusive existence of strains (ET43, ET41 and ET29) in some schoolchildren geographically related and unrelated $\left(\mathrm{D}_{n=2}\right.$ and $\mathrm{F}_{n=1}$ ), and (ii) the exclusive existence of strains in the central area or in the peripheral area.

Table 3. Allelic profiles in 75 C. albicans isolates ( 43 C. albicans strains ${ }^{\mathrm{ETs}}$ ) isolated from 75 healthy schoolchildren from eight schools located in different geographic areas (central or peripheral) of Piracicaba city, São Paulo state, Brazil.

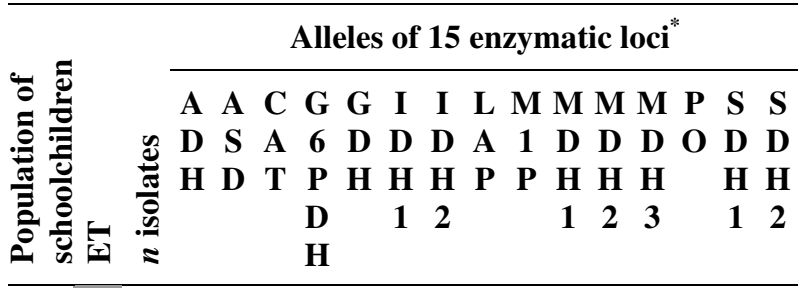

$11 a b a b a a a b b b a a$ aa aa $b b a a a b c c a b a a b b$

$71 a b b b a a b b b b$ aa aa aa bb aa ab cc ab aa bb A $10 \quad 1$ ab bbaa cc bb aa aa aa bb aa ab cc ab aa bb 311 bb bbaa cc bbaa aa aa bbaa ab cc aa aabb

321 bb bbaa cc bbaa aa aa bb aa ab cc abaabb $371 b b b b a a c c b b a a-a a b b a a a b-a a a a b b$

61 ab ab aa cc bb aa aa aa bb aa abccaaaabb

91 ab bb aa cc bb aa aa aa bb aa ab cc aa aa bb

101 ab bb aa cc bb aa aa aa bb aa ab cc ab aa bb

B 111 ab bbaa cc bbaa aa aa bbaa ab - aa aabb 201 bb ab aa cc ab ac aa aa ab aa ab cc aa aa bb 242 bb ab aa cc bb aa aa aa bb aa ab cc ab aabb

271 bb ab aa cc bb ac aa aa bb aa ab cc aa aa bb 322 bb bbaa cc bbaa aa aa bbaa abcc abaabb

211 bb ab aa cc ab ac aa aa ab aa ab cc abaabb 323 bb bb aa cc bb aa aa aa bb aa ab cc ab aa bb

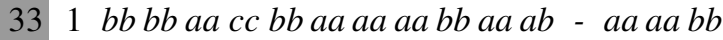

1 bb bb aa cc bbaa aa aa bbaa ab - $a b a a b b$

361 bb bbaa cc bbaa - aabbaaabcc abaabb

381 bb bbaacc bbaa - aabbaaab - abaaaa

$391 b b b b a a c c b b a a-a a b b a a a b-a b a a b b$ 401 bb bbaacc bbaa - aabbaabb-abaabb

$11 a b a b a a a b b b a a a a a a b b$ aa $a b c c a b a a b b$

161 bb ab aa aa $b b$ ac aa aa $b b$ aa $a b c c$ a $a$ aa $b b$

171 bbabaaaabb - aa aabbaa abcc abaabb

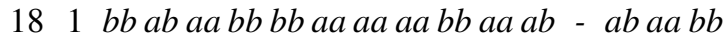

231 bbabaa cc bbaa aa aa bb aa abcc aa aabb

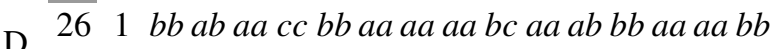

291 bbabaacc cd bb bc aa cc cc - ababaabb

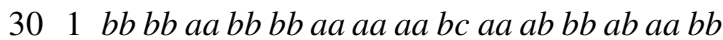

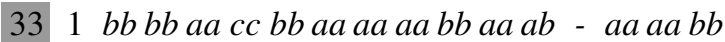

$371 b b b b a a c c b b a a-a a b b a a a b-a a a a b b$

411 bb cc bbbbabac aa aa abaaabccab-cd

\footnotetext{
${ }^{*}$ Heterozygotes are presents as $a b, a c, b c$, and $c d$. (-) null allele.
}

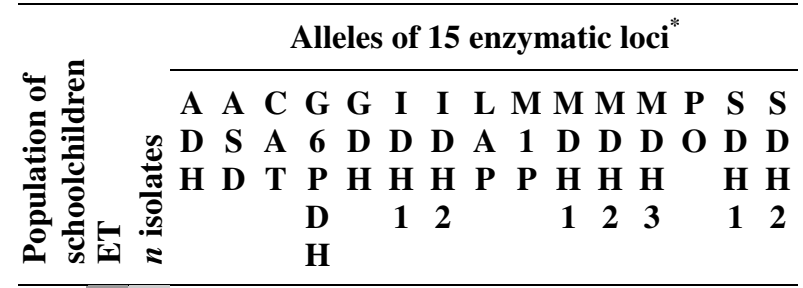

$102 a b b b a a c c b b$ aa aa $a a b b a a a b c c a b a a b b$ $141 a b b b a a c c b b a a a a a b b b a b a b$ - $a a a a b b$

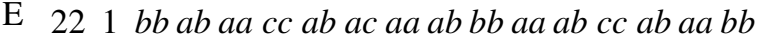
311 bb bb aa cc bb aa aa aa bb aa ab cc aa aa $b b$ 321 bb bbaa cc bb aa aa aa bb aa ab cc abaabb $51 a b a b a a c c b b$ aa aa aa bb aa ab cc aa $a a a b$ $121 a b b b a a c c b b a a a a a a b b a a a b-a b a a a b$ 232 bb ab aa cc bb aa aa aa bb aa ab cc aa $a a b b$

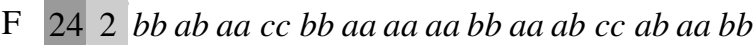
251 bb abaa cc bbaa aa aa bbaaab - abaabb 281 bb ab aa cc bb ac aa aa bb aa ab cc ab aabb 431 cc $b b a a c c b b$ aa aa cc bb aa ab cc bbaa $b b$

$21 a b a b a a b b a b a c$ aa $a a b b$ a $a$ ab cc $a b a a b b$

31 ab ab aa cc ab ac aa aa aa aa ab cc aa aa aa

41 ab ab aa cc ab ac aa aa ab aa ab cc aa $a a a b$ $81 a b b b$ aa cc bb aa aa aa bb aa ab cc aa aa $a b$ $131 a b b b a a c c b b a a a a a a b b a a a b-a b a a b b$

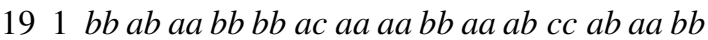

G 232 bb ab aa cc bb aa aa aa bb aa ab cc aa aa bb 242 bb ab aa cc bb aa aa aa bb aa ab cc ab aa bb 282 bb ab aa cc bb ac aa aa bb aa ab cc ab aa bb 321 bb bb aa cc bb aa aa aa bb aa ab cc ab aabb 341 bb bbaa cc bbaa aa aabbaaab - abaabb $351 b b b b a a c c b b a a-a a b b a a a b c c a a a a b b$ $421 b c b b a a c c b b a a-a a b b a a a b c c a a a a b b$

$41 a b a b a a c c a b a c$ aa $a a a b$ aa $a b c c a a a a a b$

91 ab bb aa cc bb aa aa aa bb aa ab cc aa $a a b b$ $151 a b b b a a c c b b a a-a a b b a b b b-a b a a b b$

$\mathrm{H}$ 231 bb ab aa cc bb aa aa aa bb aa ab cc aa aa $b b$ 322 bb bb aa cc bb aa aa aa bb aa ab cc ab aa bb

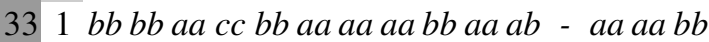
CBS-562

Type- $\quad b b b b a a c c b b a a a a a a b b a b a b c c a b a a b b$ strain 
Table 4. Measures of genetic variability in C. albicans populations isolated from oral cavity of Brazilian healthy schoolchildren.

\begin{tabular}{|c|c|c|c|c|c|c|c|c|c|c|c|c|}
\hline \multirow{2}{*}{$\begin{array}{l}\text { Population of } \\
\text { isolates }\end{array}$} & \multirow{2}{*}{$\begin{array}{l}\text { Number of } \\
\text { isolates } \\
\text { (strains \%) }\end{array}$} & \multicolumn{3}{|c|}{ Polymorphic enzyme loci } & \multicolumn{3}{|c|}{ Monomorphic enzyme loci } & \multirow{2}{*}{$\begin{array}{c}\bar{N} \text { of } \\
\text { alleles } \\
\text { per locus }\end{array}$} & \multirow{2}{*}{$\begin{array}{l}\bar{N} \text { of alleles } \\
\text { per } \\
\text { polymorphic } \\
\text { locus }\end{array}$} & \multicolumn{2}{|c|}{ Heterozygosity } & \multirow{2}{*}{$\begin{array}{l}\text { Homozygosity } \\
\text { Description }\end{array}$} \\
\hline & & $n$ & $\%$ & Description & $n$ & $\%$ & Description & & & Average & Description & \\
\hline \multicolumn{13}{|c|}{ Central geographic area } \\
\hline A & $6\left(6^{100}\right)$ & 5 & 33,3 & $\begin{array}{l}2 \text { (Adh, Asd, Mdh-2 and Po) } \\
\text { and } 3 \text { (G6pdh) alleles. }\end{array}$ & 10 & 66,7 & $\begin{array}{l}\text { (Cat, Gdh, Idh-1, Idh-2, Lap, } \\
\text { M1p, Mdh-1, Mdh-3, Sdh-1 and } \\
\text { Sdh-2 loci). }\end{array}$ & 1.40 & 2.25 & 0.391 & $\begin{array}{l}2 \text { enzymatic bands (Adh, Asd, } \\
\text { G6pdh, Mdh-2 and Po loci). }\end{array}$ & $\begin{array}{l}1 \text { (Adh, Asd, Cat, Gdh, Idh-1, Idh- } \\
\text { 2, Lap, M1p, Mdh-1, Mdh-3, Po, } \\
\text { Sdh-1 and Sdh-2 loci) and } 2 \\
\text { (G6pdh locus) alleles. }\end{array}$ \\
\hline B & $10\left(8^{80}\right)$ & 7 & 46,7 & $\begin{array}{l}2 \text { alleles (Adh, Asd, Gdh, Idh- } \\
1 \text {, M1p, Mdh-2 and Po). }\end{array}$ & 8 & 53,3 & $\begin{array}{l}\text { (Cat, G6pdh, Idh-2, Lap, Mdh-1, } \\
\text { Mdh-3, Sdh-1 and Sdh-2 loci). }\end{array}$ & 1.47 & 2 & 0.227 & $\begin{array}{l}2 \text { (Adh, Asd, Gdh, Idh-1, M1p, } \\
\text { Mdh-2 and Po loci) and } 3 \text { (Mdh-2 } \\
\text { locus) enzymatic bands. }\end{array}$ & $\begin{array}{l}1 \text { allele (Adh, Asd, Cat, G6pdh, } \\
\text { Gdh, Idh-1, Idh-2, Lap, M1p, Po, } \\
\text { Mdh-1, Mdh-3, Sdh-1 and Sdh-2 } \\
\text { loci) }\end{array}$ \\
\hline $\mathrm{C}$ & $10\left(8^{80}\right)$ & 7 & 46,7 & $\begin{array}{l}2 \text { alleles (Asd, Gdh, Idh-1, } \\
\text { M1p, Mdh-2, Po and Sdh-2 } \\
\text { loci) }\end{array}$ & 8 & 53,3 & $\begin{array}{l}\text { (Adh, Cat, G6pdh, Idh-2, Lap, } \\
\text { Mdh-1, Mdh-3 and Sdh-1 loci). }\end{array}$ & 1.47 & 2 & 0.221 & $\begin{array}{l}2 \text { (Asd, Gdh, Idh-1, M1p, Mdh-2, } \\
\text { Po and Sdh-2 loci) and } 3 \text { (Mdh-2 } \\
\text { locus) enzymatic bands. }\end{array}$ & $\begin{array}{l}1 \text { (Adh, Asd, Cat, G6pdh, Gdh, Idh- } \\
\text { 1, Idh-2, Lap, M1p, Mdh-1, Mdh-2, } \\
\text { Mdh-3, Po and Sdh-1 loci) and } 2 \\
\text { (Sdh-2 locus) alleles. }\end{array}$ \\
\hline $\mathrm{D}$ & $11\left(11^{100}\right)$ & 13 & 86,7 & $\begin{array}{l}2 \text { (Adh, Cat, Mdh-1, Mdh-2 } \\
\text { and Po loci), } 3 \text { (Asd, G6pdh, } \\
\text { Idh-1, Idh-2, M1p, Mdh-3 and } \\
\text { Sdh-2 loci) and } 4 \text { (Gdh locus) } \\
\text { alleles. }\end{array}$ & 2 & 13,3 & (Lap and Sdh-1). & 2.47 & 2.75 & 0.334 & $\begin{array}{l}2 \text { (Adh, Asd, Gdh, G6pdh, Idh-1, } \\
\text { Idh-2, M1p, Mdh-2, Mdh-3, Po and } \\
\text { Sdh-2 loci) and } 3 \text { (Mdh-2 locus) } \\
\text { enzymatic bands. }\end{array}$ & $\begin{array}{l}1 \text { (Adh, Gdh, Idh-2, Lap, Po, Sdh-1 } \\
\text { and Sdh-2 loci), } 2 \text { (Asd, Cat, Idh-1, } \\
\text { M1p, Mdh-1 and Mdh-3 loci) and } 3 \\
\text { (G6pdh locus) alleles. }\end{array}$ \\
\hline E & $6\left(5^{8.33}\right)$ & 8 & 53,3 & $\begin{array}{l}2 \text { alleles (Adh, Asd, Gdh, Idh- } \\
1 \text {, Lap, Mdh-1, Mdh-2 and Po } \\
\text { loci). }\end{array}$ & 7 & 46,7 & $\begin{array}{l}\text { (Cat, G6pdh, Idh-2, M1p, Mdh- } \\
\text { 3, Sdh-1 and Sdh-2). }\end{array}$ & 1.53 & 2 & 0.274 & $\begin{array}{l}2 \text { enzymatic bands (Adh, Asd, Gdh, } \\
\text { Idh-1, Lap, Mdh-1, Mdh-2 and Po } \\
\text { loci). }\end{array}$ & $\begin{array}{l}1 \text { allele (Adh, Asd, Cat, G6pdh, } \\
\text { Gdh, Idh-1, Idh-2, Lap, M1p, Mdh- } \\
\text { 1, Mdh-3, Po, Sdh-1 and Sdh-2 } \\
\text { loci). }\end{array}$ \\
\hline \multicolumn{13}{|c|}{ Peripheral geographic area } \\
\hline $\mathrm{F}$ & $9\left(7^{77.8}\right)$ & 7 & 46,7 & $\begin{array}{l}2 \text { (Asd, Idh-1, Lap, Mdh-2, Po } \\
\text { and Sdh-2 loci) and } 3 \text { (Adh } \\
\text { locus) alleles. }\end{array}$ & 8 & 53,3 & $\begin{array}{l}\text { (Cat, G6pdh, Gdh, Idh-2, M1p, } \\
\text { Mdh-1, Mdh-3 and Sdh-1). }\end{array}$ & 1.53 & 2.17 & 0.332 & $\begin{array}{l}2 \text { (Asd, Idh-1, Mdh-2, Po and Sdh- } \\
2 \text { loci) and } 3 \text { (Mdh-2 locus) } \\
\text { enzymatic bands. }\end{array}$ & $\begin{array}{l}1 \text { (Asd, Cat, G6pdh, Gdh, Idh-1, } \\
\text { Idh-2, M1p, Mdh-1, Mdh-3, Sdh-1 } \\
\text { and Sdh-2 loci) and } 2 \text { (Adh, Lap } \\
\text { and Po loci) alleles. }\end{array}$ \\
\hline G & $16\left(13^{81.2}\right)$ & 9 & 60,0 & $\begin{array}{l}2 \text { (Asd, G6pdh, Gdh, Idh-1, } \\
\text { M1p, Mdh-2, Po and Sdh-2 } \\
\text { loci) and } 3 \text { (Adh locus) alleles. }\end{array}$ & 6 & 40,0 & $\begin{array}{l}\text { (Cat, Idh-2, Lap, Mdh-1, Mdh-3 } \\
\text { and Sdh-1). }\end{array}$ & 1.67 & 2.12 & 0.301 & $\begin{array}{l}2 \text { (Adh, Asd, G6pdh, Gdh, Idh-1, } \\
\text { M1p, Mdh-2, Po and Sdh-2 loci) } \\
\text { and } 3 \text { (Mdh-2 locus) enzymatic } \\
\text { bands. }\end{array}$ & $\begin{array}{l}1 \text { (Adh, Asd, Cat, Gdh, Idh-1, Idh- } \\
2 \text {, Lap, Mdh-1, Mdh-3, Po and Sdh- } \\
1 \text { loci) and } 2 \text { (G6pdh, M1p and } \\
\text { Sdh-2 loci) alleles. }\end{array}$ \\
\hline $\mathrm{H}$ & $7\left(6^{85.7}\right)$ & 9 & 60,0 & $\begin{array}{l}2 \text { alleles (Adh, Asd, Gdh, Idh- } \\
1 \text {, M1p, Mdh-1, Mdh-2, Po } \\
\text { and Sdh-2 loci). }\end{array}$ & 6 & 40,0 & $\begin{array}{l}\text { (Cat, G6pdh, Idh-2, Lap, Mdh-3 } \\
\text { and Sdh-1). }\end{array}$ & 1.60 & 2 & 0.236 & $\begin{array}{l}2 \text { (Adh, Asd, Gdh, Idh-1, M1p, } \\
\text { Mdh-1, Mdh-2, Po and Sdh-2 loci) } \\
\text { and } 3 \text { (Mdh-2 locus) enzymatic } \\
\text { bands. }\end{array}$ & $\begin{array}{l}1 \text { allele (Adh, Asd, Cat, G6pdh, } \\
\text { Gdh, Idh-1, Idh-2, Lap, M1p, Mdh- } \\
\text { 1, Mdh-2, Mdh-3, Po, Sdh-1 and } \\
\text { Sdh-2 loci). }\end{array}$ \\
\hline Total & $75\left(43^{57.3}\right)$ & 14 & 93,3 & $\begin{array}{l}1 \text { (Idh-2 locus), } 2 \text { (Cat, Gdh, } \\
\text { Mdh-2, Mdh-3, Po and Sdh-2 } \\
\text { loci0 and } 3 \text { (Adh, Asd, G6pdh, } \\
\text { Idh-1, Lap, M1p and Mdh-1 } \\
\text { loci) alleles. }\end{array}$ & 1 & 6,7 & $(\mathrm{Sdh}-1)$ & 2.80 & 2.92 & 0.191 & $\begin{array}{l}2 \text { (Adh, Asd, G6pdh, Gdh, Idh-1, } \\
\text { Lap, M1p, Mdh-1, Mdh-2, Mdh-3, } \\
\text { Po and Sdh-2 loci) and } 3 \text { (Mdh-2 } \\
\text { locus) enzymatic bands. }\end{array}$ & $\begin{array}{l}1 \text { (Gdh, Idh-2, Mdh-2 and Sdh-1 } \\
\text { loci), } 2 \text { (Adh, Asd, Cat, Idh-1, Lap, } \\
\text { Mdh-1, Mdh-3, Po, and Sdh-2 loci) } \\
\text { and } 3 \text { (G6pdh and M1p loci) alleles. }\end{array}$ \\
\hline
\end{tabular}


Table 5. Distribution of the taxa and subgroups of $C$. albicans strains isolated from oral cavities of healthy schoolchildren from eight schools located in different geographic areas (central or peripheral) of Piracicaba city, São Paulo state, Brazil.

\begin{tabular}{|c|c|c|c|c|c|c|}
\hline \multirow{3}{*}{$\begin{array}{l}\text { Population of } \\
\text { Schoolchildren }\end{array}$} & \multicolumn{4}{|c|}{ Taxon A of oral yeasts $\left(d_{i j}=0.148\right)$} & \multirow{2}{*}{\multicolumn{2}{|c|}{$\begin{array}{l}\text { Taxon B of oral yeasts } \\
\text { Subgroups and Strains }\end{array}$}} \\
\hline & \multicolumn{4}{|c|}{ Subgroups and Strains $\left(0.148>d_{i j} \geq 0.038\right)$} & & \\
\hline & A1 & $\mathrm{A2}$ & A3 & A4 & B1 & B2 \\
\hline \multicolumn{7}{|l|}{ Central area } \\
\hline A & Cluster I* & Cluster III and ET7 & - & - & - & Cluster $X^{*}$ \\
\hline $\mathrm{B}$ & - & Clusters II, III and VI* & - & - & - & Cluster IX \\
\hline $\mathrm{C}$ & - & Clusters III, IV and VI* & - & - & - & Clusters VIII, $X^{*}$ and ET38 \\
\hline $\mathrm{D}$ & Cluster I*, ET17 and ET16 & Cluster II and ET30 & - & ET41 & ET29 & Clusters VIII, X* and ET18 \\
\hline $\mathrm{E}$ & - & Clusters III and VI* & - & - & - & Cluster IX \\
\hline \multicolumn{7}{|l|}{ Peripheral area } \\
\hline $\mathrm{F}$ & - & Clusters II and V** & ET43 & - & - & Cluster VIII and ET12 \\
\hline G & - & $\begin{array}{l}\text { Clusters II, III, IV, V**, } \\
\text { VII**, ET2 and ET } 19\end{array}$ & - & - & - & Clusters VIII and IX \\
\hline $\mathrm{H}$ & - & Clusters II, III and VII** & - & - & - & Cluster VIII and ET15 \\
\hline
\end{tabular}

* Clusters of $C$. albicans isolated exclusively from oral cavities of healthy schoolchildren from the central geographic area.

** Clusters of C. albicans isolated exclusively from oral cavities of healthy schoolchildren from the peripheral geographic area.

\section{DISCUSSION}

The strain delineation by multilocus enzyme electrophoresis (MLEE) has allowed the evaluation of the genetic diversity and structure of populations (43), as well as provided high discriminatory power and reproducibility $(5,7$, 9, 34, 42, 67). Considered as neutral markers (invariable when they suffer environmental selective pressures), the metabolic isoenzymes have presented a great potential in taxonomic, systematic, genetic, evolutive and epidemiologic characterization of $C$. albicans and other yeasts of medical importance $(3-5,8-11,13,42-44,53)$. In this study the enzyme profiles of the $C$. albicans samples on different gels were reproducible after three repetitions of each electrophoretic run.

Genetic polymorphism has been found in almost all natural populations and at all levels of genetic organization, from genotypic characteristics to phenotypic traits. The possible reasons of its existence have been the object of a long debate in population genetics and molecular evolution $(19,20$, 26). A certain structural genetic locus is defined as polymorphic when the frequency of its more common allele presents a value below 0.99 (99\%). Some measurements used to quantify this variability in diploid organisms populations are the gene and allele frequencies, the polymorphic loci percentage, the average number of alleles per locus, the average number of alleles per polymorphic locus and the heterozygosity $(22,37)$. In this study, quantitative and qualitative variations of the polymorphic loci (5 to 13 , average of $8.125 \pm 2.356$ ), of the average number of alleles per locus (1.40 to 2.47 , average of $1.642 \pm 0.344$ ) and of the average number of alleles per polymorphic locus ( 2 to 2.75 , average of $2.161 \pm 0.256)$ were observed in all C. albicans populations isolated from oral cavities of healthy schoolchildren. These variations have been observed in several genetic diversity studies of $C$. albicans populations isolated from immunocompromised and immunocompetent patients $(8,9,13$, 27, 42-44). Pujol et al. (43) reported that different allelic frequencies in different populations can be associated with geographic isolation, the same as when each separate population remains in panmixia. The average heterozygosis found in the $C$. albicans total population was equal to 0.191 . The $C$. albicans populations isolated from healthy schoolchildren coming from A, B, C, D, E, F, G and H schools 
showed average heterozygosity values equal to $0.391,0.332$, $0.277,0.301,0.221,0.334,0.274$, and 0.236 , respectively. In a similar way to previous results by MLEE studies $(11,15,52$, 53), the heterozygotic patterns obtained in this study were consistent with the diploid nature of C. albicans (54). In addition, the heterozygosity reduction in the population structure of certain organisms can be interpreted as a group of interconnected strains (22).

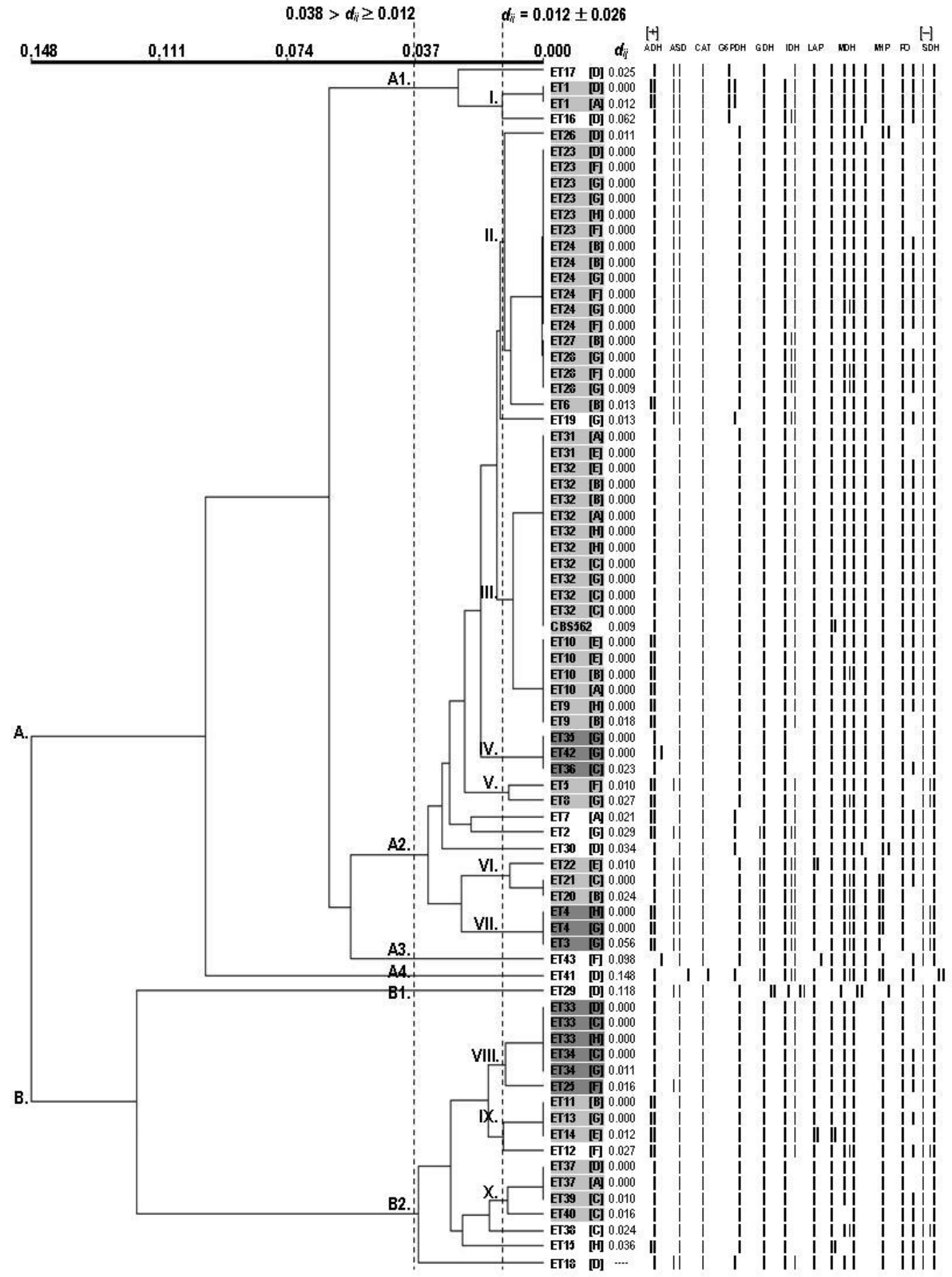

Figure 1. Genetic diversity of C. albicans isolated from oral cavities of 75 healthy schoolchildren from eight schools located in different geographic areas (central or peripheral) of Piracicaba city, São Paulo state, Brazil. UPGMA dendrogram $\left(r_{j k}=0.92513-\right.$ very good fit) generated from Nei's matrix of genetic distance $d_{i j}$ (45). Threshold: $0.012>d_{i j} \geq 0$ (highly related or ideptigge isolates); $0.038>d_{i j} \geq 0.012$ (moderately related isolates). 
In this study, the high genetic diversity found in oral isolates of $C$. albicans showed a polyclonal pattern of colonization within and between groups of healthy schoolchildren ( $\mathrm{A}_{6 \mathrm{ETs}}, \mathrm{B}_{7 \mathrm{ETs}}, \mathrm{C}_{8 \mathrm{ETs}}, \mathrm{D}_{13 \mathrm{ETs}}, \mathrm{E}_{8 \mathrm{ETs}}, \mathrm{F}_{11 \mathrm{ETs}}, \mathrm{G}_{5}$ ETs and $\mathrm{H}_{6 \mathrm{ETs}}$ ) located in different geographic areas (central or peripheral) of Piracicaba city, São Paulo state, Brazil. However, monoclonal patterns were observed within 6 populations of students ( $\mathrm{B}_{\text {ET24 and ET32, }} \mathrm{C}_{\text {ET32 }}, \mathrm{E}_{\text {ET10 }}, \mathrm{F}_{\mathrm{ET} 23 \text { and }}$

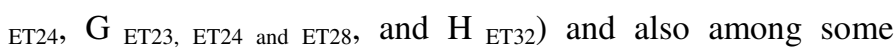
populations ( $\mathrm{A}$ and $\mathrm{D}_{\mathrm{ET} 1} ; \mathrm{H}$ and $\mathrm{G}_{\mathrm{ET} 4} ; \mathrm{B}$ and $\mathrm{H}_{\mathrm{ET} 9} ; \mathrm{A}, \mathrm{B}$ and $\mathrm{E}$ ET10; D, F, G and $\mathrm{H}_{\mathrm{ET} 23} ; \mathrm{B}, \mathrm{F}$ and $\mathrm{G}_{\mathrm{ET} 24} ; \mathrm{F}$ and $\mathrm{G}_{\mathrm{ET} 28} ; \mathrm{A}$ and $\mathrm{E}$ ET31 ; A, B, C, E, G and $\mathrm{H}_{\text {ET32) }}$; C, D and $\mathrm{H}_{\mathrm{ET} 33}$; $\mathrm{C}$ and $\mathrm{G}_{\mathrm{ET} 34}$; $\mathrm{A}$ and $\left.\mathrm{D}_{\mathrm{ET} 37}\right)$ in different geographic areas (central or peripheral). These data provide evidence of the high genetic diversity of $C$. albicans strains in populations of healthy schoolchildren, which can be geographically widespread. Nevertheless, it also suggests the existence of strains selected and better adapted than others, to the oral cavities of those healthy schoolchildren.

The existence of Candida spp. strains selected and better adapted to certain human niches (68), possible intraspecies competition, which could be altered by selective pressure of antifungal treatments (45), or even, infection acquired from an exogenous source (31), have also been reported. PCR fingerprinting analysis showed clonality of $C$. albicans isolated from $\mathrm{HIV}^{+}$patients (Durham, A.D. and Vitória, Brazil) within and among geographically different populations (75). In other MLEE typing studies, the high genetic diversity of $C$. albicans strains isolated from $\mathrm{HIV}^{+}$patients living within a limited geographic area (Montpellier, France) could be associated to some geographically widespread clonal strains (44), as is the case of some bacteria $(61,62)$ and protozoa $(70,72)$. Although certain strains were identified exclusively in a certain population of schoolchildren, no correlation was observed between $C$. albicans strain and population of healthy schoolchildren or geographic site (i.e., central or peripheral areas). Additionally, within the populations of $C$. albicans significant divergence between observed and expected genotypic frequencies (Hardy-Weinberg equilibrium test) was not detected - data not showed. Such observations suggest the hypothesis that populations of healthy schoolchildren do not correspond to the selection factor (differential survival) of $C$. albicans strains (ETs). In contrast to the high genetic diversity of C. albicans observed in populations of healthy schoolchildren, a low genetic diversity has been detected by MLEE analysis in $C$. albicans isolated from different anatomical sites (oral cavity, groin, feces) of immunocompromised patients, with or without symptoms of candidiasis, from several geographic areas (Abdjan, Ivory Coast; Lausanne, Switzerland; Montpellier, France; Oslo, Norway), however, without any correlation to the clinical parameters, anatomical sites or antifungal susceptibility (AMB, FCZ, Flucytosine, ITZ, KTZ and NYS) (8, 9, 13, 27, 35, 45).

In this study, the genetic relationships between $C$. albicans oral strains was successfully explained using Nei's distance $d_{i j}$ (36) and UPGMA dendrogram $(18,65,66)$, according to the Pearson product-moment correlation coefficient value $\left(r_{j k}=\right.$ 0.92513) [i.e. high concordance between the $d_{i j}$ (genetic distance matrix) and $C_{j k}$ elements (correlation matrix derived from UPGMA dendrogram)]. Two taxa (A and B), six subgroups (A1, A2, A3, A4, B1 and B2) and ten clusters (taxon A: I of out VII; taxon B: VIII of out X) were identified in the total population of yeasts. These observations suggest the existence of two large, highly polymorphic, distantly genetically related taxa of $C$. albicans, in the oral cavities of healthy schoolchildren from the central and peripheral geographic areas of the city of Piracicaba, state of São Paulo, Brazil. The subgroups comprised strains and/or clusters of strains moderately related colonizing the oral cavities of healthy schoolchildren (or populations of healthy schoolchildren) from the central area (clusters I, VI and X), peripheral area (clusters V and VII) or both geographical areas (clusters II, III, IV, VIII and XI), but no specificity between particular clusters and populations of healthy schoolchildren. These data suggest the existence of subgroups of moderately related and 
geographically limited or unlimited strains, within the city of Piracicaba, and therefore possible sources or routes of propagation or oral transmission of $C$. albicans. These subgroups could also be better adapted to oral niches in certain populations of healthy schoolchildren. Therefore, the genetic and environmental factors of each healthy schoolchild (or population) could be investigated concurrently with the prevalence of their respective subgroups of $C$. albicans strain to elucidate their degrees of specificity for different adaptations. Conversely, the clusters identified as identical or highly related strains suggest (i) the coexistence of strains in healthy schoolchildren geographically related and/or unrelated, (ii) the exclusive existence of strains in some schoolchildren geographically related and/or unrelated, (iii) the exclusive existence of strains in the central area or the peripheral area, and (iv) the coexistence of strains in both central and peripheral areas. Considering that highly related strains come from a common ancestor [(i.e., descendants have undergone microevolution and adaptations as a consequence of the loss of heterozygosity, mitotic recombination, chromosomal rearrangement of repetitive sequences in tandem and subtelomeric and telomeric sequences, chromosomal alterations or genetic expression control $(12,14,27,45,47-49,54,67)$, these data reinforce the hypothesis of oral transmission of $C$. albicans among related healthy schoolchildren, where the sources of propagation (i.e., school environments, classrooms, dining halls, bathrooms, private and public libraries, food, water, air conditioners, oral hygiene, asymptomatic students, teachers and employees, and others) could be explored.However, the existence of "general-purpose genotypes" between populations of healthy children living in geographically adjacent regions, where little radial spread of strains can happen, remains an intriguing hypothesis to be confirmed.

Ca3 fingerprinting has shown that a single cluster of genetically related infection-causing $C$. albicans isolates usually predominates in a given patient population in a given geographic location $(23,40,56-59)$, and that the genetic distance among isolates from different regions exceeds that among isolates from same region, indicating regional specificity of C. albicans (40, 57). Such regional specificity could be caused by independent clonal evolution within individual regions of sets of ancestral strains common to all regions (55). A neighbor-joining and an unrooted phylogram tree based on $\mathrm{Ca} 3$ fingerprinting patterns of 266 infection-causing C. albicans isolates (female, male, AIDS, neutropenia, lower gastrointestinal tract, urine, vaginal, upper respiratory tract, oral, sterile site, skin and wounds), each from a separate patient exhibiting symptoms of candidiasis and/or carrying levels of Candida exceeding those for commensal colonization, from eighteen geographic locations in 6 countries (Iowa, USA; Michigan, USA; Medellin, Colombia; Leicester, UK; London, UK; Bangor, Southampton, Oxford, Manchester, Welwyn, Basildon and Cardiff, UK; Kuala Lumpur, Malaysia; Suva, Fiji; Auckland, New Zealand; Wellington, New Zealand; Christchurch, New Zealand; Otago, New Zealand) was generated in order to determine if a geographically widespread highly prevalent group of $C$. albicans strains exists (55). In that research, a group of highly similar C. albicans isolates, designated cluster $\mathrm{A}$, with a high prevalence across a variety of geographical regions, patient types and types of infections, was identified, indicating that this group constitutes the predominant aetiological agent of candidiasis ("general-purpose genotypes"). However, two other clusters considerably less successful, designated $\mathrm{B}$ and $\mathrm{C}$, may also contain general-purpose genotypes. No significant correlation was observed between the geographical distance between two regions and the genetic distance between isolates, suggesting that there was little radial spread of strains among geographically adjacent regions. Using MLEE and cluster analyses, other researchers showed clusters composed of highly related $C$. albicans strains isolated from healthy and immunocompromised patients (Montpellier, France; Lausanne, Switzerland; Abidjan, Ivory Coast) without correlations with the clinical aspects, antifungal susceptibility or geographic regions $(9,27,35,42)$. Karyotyping analyses has also identified similar $C$. albicans clusters displaying prevalence in healthy individuals and $\mathrm{HIV}^{+}$patients (Pisa, Italy), suggesting that commensal strains can be probable agents of subsequent oral 
candidiasis in immunocompromised patients, despite the possibility of substitution of strains occurring $(30,41,73)$. Clemons et al. (15) conducted a comparative genotypic analysis of Candida albicans isolates from the United States, Europe, and Southeast Asia to determine whether differences between isolates might be associated with geographic locations. Genotypes of unrelated isolates of $C$. albicans were examined by three DNA typing (REA with EcoRI, RAPD and PFGE) and computer-assisted methods. Despite the discriminatory differences that exist between each of these methods of genotyping the REA and RAPD analysis showed an epidemiologic clustering of the Southeast Asian isolates of $C$. albicans that was distinct from that of the closely related U.S. and European isolates. These results indicated that high genetic diversity exists between isolates of $C$. albicans derived from Southeast Asia and those derived from the United States or Europe.

Analysis of a polymorphic microsatellite locus (CEF3 gene - promoter region of the elongation factor 3) was applied to 85 Candida albicans strains from healthy individuals (group A) (16) and compared with strains from non-healthy individuals (groups $\mathrm{B}$ and $\mathrm{C}$, i.e., bloodstream and nonbloodstream $C$. albicans strains obtained from patients treated in a tertiary-care hospital) (17). These analyses showed the overall genetic diversity at the $C E F 3$ locus slightly higher in group $\mathrm{A}$ than in the pooled groups $\mathrm{B}$ and $\mathrm{C}$, and also the exclusivity of some genotypes for each group or the coexistence of the majority of genotypes between the groups, suggesting that the ability to undergo increased mucosal proliferation in non-healthy individuals is a widespread biological property, common to most $C$. albicans genotypes (i.e., all commensal strains have the ability to develop as pathogens). This fact was consistent with other studies that have addressed the relationship between genotypes and commensalism or pathogenicity in $C$. albicans $(6,31,73,74)$. In order to test the possibility that genetically distinct $C$. albicans strains are associated with oropharyngeal colonization of $\mathrm{HIV}^{+}$individuals, oral isolates from $\mathrm{HIV}^{+}$patients visiting three clinics in South Africa and control isolates from healthy individuals (healthy black and white South Africans) were analyzed using DNA fingerprinting with the complex probe $\mathrm{Ca} 3$ and cluster analysis (6). In addition, the groups identified in these cluster analyses were compared to the three groups of C. albicans isolates (groups I, II, and III) previously identified in collections of U.S. isolates by a variety of fingerprinting methods $(29,42)$. This comparison revealed a new group, or clade, of C. albicans in South Africa (group SA) that (i) was absent in the United States, (ii) accounted for 53\% of isolates in $\mathrm{HIV}^{+}$and healthy black South Africans and 33\% of isolates in healthy white South Africans, and (iii) was less closely related to groups I, II, and III than these three groups were to each other. However, no strain revealed specificity for $\mathrm{HIV}^{+}$ oropharyngeal infections. The proportions of group I, II, III, and SA isolates causing oropharyngeal infections were similar to the proportions of these groups in $\mathrm{HIV}^{+}$individuals exhibiting no signs of infection and were similar to the proportions in healthy black South Africans. Finally, the predominance of SA isolates in South Africans suggested that this group is the most successful as both, a commensal and pathogenic organism in that geographic area (6). More recently, multilocus sequence typing (MLST) of $C$. albicans isolates (mouth and stool) revealed frequent colonization of a subject or several members of the same family (patients with Crohn's disease and their unaffected family members from northern Belgium) by genetically indistinguishable or genetically close isolates (12). These findings also demonstrated that intrafamilial transmission is highly frequent and is a potential source of contamination between humans, which is in agreement with previously published data $(25,32)$. However, isolates within an individual or a family can differ through microevolution in one or several of the sequenced MLST loci. These microevolutions are always associated with a loss of heterozygosity ( $\mathrm{LOH})$, suggesting a predominant contribution of mitotic recombination events during the evolution of commensal isolates (12).

The current study reported high genetic diversity of $C$. 
albicans oral strains and patterns of monoclonal and polyclonal colonization within and between the groups of healthy schoolchildren located in different geographic areas (central or peripheral) of Piracicaba city, São Paulo state, Brazil, suggesting strains selected and better adapted than others in the oral cavities of those healthy schoolchildren. Significant divergence between observed and expected genotypic frequencies of $C$. albicans (Hardy-Weinberg equilibrium test) was not detected in the geographically adjacent groups, suggesting the hypothesis that populations of healthy schoolchildren do not correspond to the selection factor (differential survival) of strains. Two taxa (A and B), six subgroups (A1, A2, A3, A4, B1 and B2) and ten clusters (taxon A: I of out VII; taxon B: VIII of out X) were identified within the total population of yeasts suggesting the existence of moderately related and geographically limited or unlimited subgroups, and, therefore, possible sources and routes of propagation or oral transmission of $C$. albicans. In addition, the coexistence of strains in geographically related healthy schoolchildren reinforces such hypothesis of oral transmission. The analysis of genetic diversity of oral $C$. albicans isolated from healthy schoolchildren using MLEE and cluster analysis contributes to the studies on biodiversity and molecular epidemiology of this specie. Furthermore, such procedure could also be used during current and retrospective analyses of $C$. albicans isolated from immunocompetent and immunocompromised individuals or students, in order to detect the existence of a commensal or potentially pathogenic yeast group predominant in candidiasis. It could lead to development of strategies for prevention of its transmissibility or human propagation.

\section{ACKNOWLEDGEMENT}

This research was supported by FAPESP (Fundação de Amparo à Pesquisa do Estado de São Paulo). The authors also thank Prof. Martin Webster for English language revision.

\section{REFERENCES}

1. Akpan, A.; Morgan, R. (2002). Oral candidosis, Postgraduate Medical
Journal 78: 455-459.

2. Alfenas, A.C. (1998). Eletroforese de isoenzimas e proteínas afins fundamentos e aplicações em plantas e microrganismos. $2^{\text {nd }}$ ed. Viçosa, MG.

3. Arnavielhe, S.; Blancark, A.; Mallié, M.; Quilici, M.; Bastide, J.M. (1997). Multilocus enzyme electrophoresis analysis of Candida albicans isolates from three intensive care units. An epidemiological study. Mycoses 40: 159-167.

4. Barchiesi, F.; Arzeni, D.; Del Prete, M.S.; Cínico, A.; Falconi Di Francesco, L.; Pasticci, M.B.; Lamura, L.; Unzo M.M.; Burzacchini, F.; Coppola, S.; Chiodo, F.; Scalise, G. (1998). Fluconazole susceptibility and strain variation of Candida albicans isolates from HIV-infected patients with oropharyngeal candidosis. J. Antimicrob. Chem. 41: 541548.

5. Bertout, S.; Renaud, F.; Swinne, D.; Mallie, M.; Bastide, J-M. (1999). Genetic multilocus studies of different strains of Cryptococcus neoformans: taxonomy and genetic structure. J. Clin. Microbiol. 37: 715720 .

6. Blignaut, E.; Pujol, C.; Lockhart, S.; Joly, S.; Soll, D.R. (2002). Ca3 Fingerprinting of Candida albicans isolates from human immunodeficiency virus-positive and healthy individuals reveals a new clade in South Africa. J. Clin. Microbiol. 40: 826-836.

7. Boerlin, P. (1997). Applications of multilocus enzyme electrophoresis in medical microbiology. J. Microbiol. Meth 28: 221-231.

8. Boerlin, P.; Boerlin-Petzold, F.; Durussel, C.; Addo, M.; Pagani, J-L.; Chave, J-P.; Bille, J. (1995). Cluster of oral atypical Candida albicans isolates in a group of human immunodeficiency virus-positive drug users. J. Clin. Microbiol. 33: 1129-1135.

9. Boerlin, P.; Boerlin-Petzold, F.; Goudet, J.; Durussel, C.; Pagani, J-L.; Chave, J-P.; Bille, J. (1996). Typing Candida albicans oral isolates from human immunodeficiency virus-infected patients by multilocus enzyme electrophoresis and DNA fingerprinting. J. Clin. Microbiol. 34: 12351248.

10. Boriollo, M.F.G.; Bassi, R.C.; Nascimento, C.M.G.S; Feliciano, L.M.; Francisco, S.B.; Barros, L.M.; Spolidório, L.C.; Spolidório, D.M.P. (2009). Distribution and hydrolytic enzyme characteristics of Candida albicans strains isolated from diabetic patients and their non-diabetic consorts . Oral Microbiol. Immunol. 24: 437-450.

11. Boriollo, M.F.G.; Rosa, E.A.R.; Gonçalves, R.B.; Höfling, J.F. (2006). Parity among interpretation methods of MLEE patterns and disparity among clustering methods in epidemiological typing of Candida albicans. J. Microbiol. Methods 64: 346-365.

12. Bougnoux, M-E.; Diogo, D.; François, N.; Sendid, B.; Veirmeire, S.; Colombel, J.F.; Bouchier, C.; Van Kruiningen, H.; d'Enfert, C.; Poulain, D. (2006). Multilocus sequence typing reveals intrafamilial transmission and microevolutions of Candida albicans isolates from the human digestive tract. J. Clin. Microbiol. 44: 1810-1820. 
13. Caugant, D.A.; Sandven, P. (1993). Epidemiological analysis of Candida albicans strains by multilocus enzyme electrophoresis. J. Clin. Microbiol. 31: 215-220.

14. Chibana, H.; Iwaguchi, S-I.; Homma, M.; Chindamporn, A.; Nakagawa, Y.; Tanaka, K. (1994). Diversity of tandemly repetitive sequences due to short periodic repetitions in the chromosomes of Candida albicans. J. Bacteriol. 176: 3851-3858.

15. Clemons, K.V.; Feroze, F.; Holmberg, K.; Stevens, D.A. (1997) Comparative analysis of genetic variability among Candida albicans isolates from different geographic locales by three genotypic methods. $J$. Clin. Microbiol. 35: 1332-1336.

16. Dalle, F.; Dumont, L.; Franco, N.; Mesmacque, D.; Caillot, D.; Bonnin, P.; Moiroux, C.; Vagner, O.; Cuisenier, B.; Lizard, S.; Bonnin, A. (2003). Genotyping of Candida albicans oral strains from healthy individuals by polymorphic microsatellite locus analysis. J. Clin. Microbiol. 41: 2203-2205.

17. Dalle, F.; Franco, N.; Lopez, J.; Vagner, O.; Caillot, D.; Chavanet, P.; Cuisenier, B.; Aho, S.; Lizard, S.; Bonnin, A. (2000). Comparative genotyping of Candida albicans bloodstream and nonbloodstream isolates at a polymorphic microsatellite locus. J. Clin. Microbiol. 38: 4554-4559.

18. Farris, J.S. (1969). On the cophenetic correlation coefficient. Syst. Zool. 18: 279-285.

19. Gillespie, J.H. (1991). The causes of molecular evolution. Oxford University Press, N.Y.

20. Golding, B. (1994). Non-neutral evolution. Chapman and Hall, N.Y.

21. Harris, H.; Hopkinson, D.A. (1976). Handbook of enzyme electrophoresis in human genetics. (And Supplement 1978) NorthHolland Publishing Co., Amsterdam.

22. Hartl, D.L.; Clark, A.G. (1997). Principles of population genetics. Sinauer Associates, Inc. Publishers Suderland, Mass.

23. Hellstein, J.; Vawter-Hugart, H.; Fotos, P.; Schmid, J.; Soll, D.R. (1993). Genetic similarity and phenotypic diversity of commensal and pathogenic strains of Candida albicans isolated from the oral cavity. $J$. Clin. Microbiol. 31: 3190-3199.

24. Hunter, P.R. (1991). A critical review of typing methods for Candida albicans and their applications. Crit. Rev. Microbiol. 17: 417-434.

25. Kam, A.P.; Xu, J. (2002). Diversity of commensal yeasts within and among healthy hosts. Diagn. Microbiol. Infect. Dis. 43: 19-28.

26. Kimura, M. (1983). The neutral theory of molecular evolution. Cambridge University Press, UK.

27. Le Guennec, R.; Reynes, J.; Mallie, M.; Pujol, C.; Janbon, F.; Bastide, JM. (1995). Fluconazole- and itraconazole-resistant Candida albicans strain from AIDS patients: multilocus enzyme electrophoresis analysis and antifungal susceptibilities. J. Clin. Microbiol. 33: 2732-2737.

28. Lehmann, P.F.; Lin, D.; Lasker, B.A. (1992). Genotypic identification and characterization of species and strains within the genus Candida by using random amplified polymorphic DNA. J. Clin. Microbiol. 30: 32493254.

29. Lott, T.J.; Logan, D.A.; Holloway, B.P.; Fundyga, R.; Arnold, J. (1999). Towards understanding the evolution of the human commensal yeast, Candida albicans. Microbiology 145: 1137-1143.

30. Lupetti, A.; Guzzi, G.; Paladini, A.; Swart, K.; Campa, M.; Senesi, S. (1995). Molecular typing of Candida albicans in oral candidiasis: karyotype epidemiology with human immunodeficiency virusseropositive patients in comparison with that with healthy carriers. $J$. Clin. Microbiol. 33: 1238-1242.

31. Luu, L.N.; Cowen, L.E.; Sirjusingh, C.; Kohn, L.M..; Anderson, J.B. (2001). Multilocus genotyping indicates that the ability to invade the bloodstream is widespread among Candida albicans isolates. J. Clin. Microbiol. 39: 1657-1660.

32. Mehta, S.K.; Stevens, D.A.; Mishra, S.K.; Feroze, F.; Pierson, D.L. (1999). Distribution of Candida albicans genotypes among family members. Diagn. Microbiol. Infect. Dis. 34: 19-25.

33. Moreira, D.; Spolidório, D.M.P.; Rodrigues, J.A.O.; Boriollo, M.F.G.; Pereira, C.V.; Rosa, E.A.R.; Höfling, J.F. (2001). Candida spp. biotypes in the oral cavity of school children from different socioeconomic categories in Piracicaba - SP, Brazil. Pesq. Odont. Bras. 15: 187-195.

34. Murphy, R.W.; Sites, J.W.; Buth, D.G.; Haufler, C.H. (1990). Proteins I: isoenzyme electrophoresis. In: Hillis DM, Moritz C (eds), Molecular systematics, Sinauer Associates Inc. Publishers, Sunderland, Mass, pp. 45-126.

35. Nébavi, F.; Arnavielhe, S.; Le Guennec, R.; Ménan, E.; Kacou, A.; Combe, P.; Aoussi, E.; Mallié, M.; Koné, M.; Bastide, J.M. (1998). Oropharyngeal candidiasis in AIDS patients from Abidjan (Ivory Coast): antifungal susceptibilities and multilocus enzyme electrophoresis analysis of Candida albicans isolates. Pathol. Biol. 46: 307-314.

36. Nei, M. (1972). Genetic distances between populations. Am. Naturalist 106: 283-292.

37. Nei, M. (1987). Molecular evolutionary genetics. Columbia University Press, New York.

38. Pasteur, N.; Pasteur, G.; Bonbomme, F.; Catalan, J.; Britton-Davidian, J. (1987). Manuel technique de génétique par électrophorèse dês protéines. Technique et documentation. Lavoisier, Paris.

39. Pfaller, M.A.; Diekema, D.J. (2007). Epidemiology of invasive candidosis: a persistent public health problem. Clin. Microbiol. Rev. 20: 133-163.

40. Pfaller, M.A.; Lockhart, S.R.; Pujol, C.; Swails-Wenger, J.A.; Messer, S.A.; Edmond, M.B.; Jones, R.N.; Wenzel, R.P.; Soll, D.R. (1998). Hospital specificity, region specificity, and fluconazole resistence of Candida albicans bloodstream isolates. J. Clin. Microbiol. 36: 15181529. 
41. Powderly, W.G.; Robinson, K.; Keath, E.J. (1992). Molecular typing of Candida albicans isolated from oral lesions of HIV-infected individuals. AIDS 6: 81-84.

42. Pujol, C.; Joly, S.; Lockhart, S.R.; Noel, S.; Tibayrenc, M.; Soll, D.R. (1997). Parity among the randomly amplified polymorphic DNA method, multilocus enzyme electrophoresis, and southern blot hybridization with the moderately repetitive DNA probe $\mathrm{Ca} 3$ for fingerprinting Candida albicans. J. Clin. Microbiol. 35: 2348-2358.

43. Pujol, C.; Reynes, J.; Renaud, F.; Mallie, M.; Bastide, J.M. (1993a). Genetic analysis of Candida albicans strains studies by isoenzyme electrophoresis. J. Mycol. Med. 3: 14-19.

44. Pujol, C.; Reynes, J.; Renaud, F.; Raymond, M.; Tibayrenc, M.; Ayala, F.J.; Janbon, F.; Mallie, M.; Bastide, J.M. (1993b). The yeast Candida albicans has a clonal mode of reproduction in a population of infected human immunodeficiency virus-positive patients. Proc. Natl. Acad. Sci. USA 90: 9456-9459.

45. Reynes, J.; Pujol, C.; Moreau, C.; Mallié, M.; Renaud, F.; Janbon, F.; Bastide, J.M. (1996). Simultaneous carriage of Candida albicans strains from HIV-infected patients with oral candidiasis: multilocus enzyme electrophoresis analysis. FEMS Microbiol. Lett. 137: 269-273.

46. Rohlf, F.J. (1988). NTSYS-pc numerical taxonomy and multivariate analysis system. Exeter Software Publishing, New York.

47. Rustchenko, E.P.; Howard, D.H.; Sherman, F. (1994). Chromosomal alterations of Candida albicans are associated with the gain and loss of assimilating functions. J. Bacteriol. 176: 3231-3241.

48. Rustchenko-Bulgac, E.P.; Sherman, F.; Hicks, J.B. (1990). Chromosomal rearrangements associated with morphological mutants provide a means for genetic variation of Candida albicans. J. Bacteriol. 172: 1276-1283.

49. Sadhu, C.; McEachern, M.J.; Rustchenko-Bulgac, E.P.; Schmid, J.; Soll, D.R.; Hicks, J.B. (1991). Telomeric and dispersed repeat sequences in Candida yeasts and their use in strain identification. J. Bacteriol. 173: 842-850.

50. Samaranayake, L.P.; MacFarlane, T.W.; Lamey, P.J.; Ferguson, M.M. (1986). A comparison of oral rinse and imprint sampling techniques for the detection of yeast, coliform and Staphylococcus aureus carriage in the oral cavity. J. Oral Pathol. 15: 386-388.

51. Samaranayake, L.P. (1990). Oral candidosis: an old disease in new guises. Dent Update 17: 36-38.

52. Samaranayake, Y.H.; Samaranayake, L.P.; Pow, E.H.; Beena, V.T.; Yeung, K.W. (2001). Antifungal effects of lysozyme and lactoferrin against genetically similar, sequential Candida albicans isolates from a human immunodeficiency virus-infected southern Chinese cohort. $J$. Clin. Microbiol. 39: 3296-3302.

53. San Millan, R.M.; Wu, L.C.; Salkin, I.F.; Lehmann, P.F. (1997). Clinical isolates of Candida guilliermondii include Candida fermentati. Int. J. Syst. Bacteriol. 47: 385-393
54. Scherer, S.; Magee, P.T. (1990). Genetics of Candida albicans. Microbiol. Rev. 54: 226-241.

55. Schmid, J.; Herd, S.; Hunter, P.R.; Cannon, R.D.; Yasin, M.S.M.; Samad, S.; Carr, M.; Parr, D.; McKinney, W.; Schousboe, M.; Harris, B.; Ikram, R.; Harris, M.; Restrepo, A.; Hoyos, G.; Singh, K.P. (1999). Evidence for a general-purpose genotype in Candida albicans, highly prevalent in multiple geographical regions, patient types and types of infection. Microbiology 145: 2405-2413.

56. Schmid, J.; Hunter, P.R.; White, G.C.; Nand, A.K.; Soll, D.R. (1995a). Physiological traits associated with success of Candida albicans strains as commensal colonizers and pathogens. J. Clin. Microbiol. 33: 29202926.

57. Schmid, J.; Rotman, M.; Reed, B.; Pierson, C.L.; Soll, D.R. (1993). Genetic similarity of Candida albicans strains from vaginitis patients and their partners. J. Clin. Microbiol. 31: 39-46.

58. Schmid, J.; Tay, Y.P.; Wan, L.; Carr, M.; Parr, D.; McKinney, W. (1995b). Evidence for nosocomial transmission of Candida albicans obtained by Ca3 fingerprinting. J. Clin. Microbiol. 33: 1223-1230.

59. Schmid, J.; Voss, E.; Soll, D.R. (1990). Computer-assisted methods for assessing strain relatedness in Candida albicans by fingerprinting with the moderately repetitive sequence Ca3. J. Clin. Microbiol. 28: 12361243.

60. Segal, E.; Baum, G.L. (1994). Pathogenic yeasts and yeast infections. Boca Raton, FL: CRC Press, Inc.

61. Selander, R.K.; Levin, B.R. (1980). Genetic diversity and structure in Escherichia coli populations. Science 210: 545-547.

62. Selander, R.K.; Musser, J.M.; Caugant, D.A.; Gilmour, M.N.; Whittam, T.S. (1987). Population genetics of pathogenic bacteria. Microb. Pathog. 3: $1-7$.

63. Selander, R.K.; Caugant, D.A.; Ochman, H.; Musser, J.M.; Gilmour, M.N.; Whittam, T.S. (1986). Methods of multilocus enzyme electrophoresis for bacterial population genetics and systematics. Appl. Environ. Microbiol. 51: 873-884.

64. Silveira, F.R.X.; Paula, C.R.; Birman, E.G.; Cambale, W. (1995). Candida albicans isolates from the oral mucosa of healthy carriers. Rev. Microbiol. São Paulo 26: 279-283.

65. Sneath, P.H.A.; Sokal, R.R. (1973). Numerical taxonomy. W. H. Freeman and Company. San Francisco, California.

66. Sokal, R.R.; Rohlf, F.J. (1970). The intelligent ignoramus, an experiment in numerical taxonomy. Taxon 19: 305-319.

67. Soll, D.R. (2000). The ins and outs of DNA fingerprinting the infectious fungi. Clin. Microbiol. Rev. 13: 322-370.

68. Soll, D.R.; Galask, R.; Schmid, J.; Hanna, C.; Mac, K.; Morrow, B. (1991). Genetic dissimilarity of commensal strains of Candida spp. carried in different anatomical localizations of the same healthy women. J. Clin. Microbiol. 29: 1702-1710. 
69. Stenderup, A. (1990). Oral mycology. Acta Odont. Scand. 48: 3-10.

70. Tibayrenc, M.; Kjellberg, F.; Arnaud, J.; Oury, B.; Breniere, S.F.; Darde, M.L.; Ayala, F.J. (1991). Are eukaryotic microorganisms clonal or sexual? A population genetics vantage. Proc. Natl. Acad. Sci. USA 88 5129-5133.

71. Tibayrenc, M.; Kjellberg, F.; Ayala, F.J. (1990). A clonal theory of parasitic protozoa: the population structures of Entamoeba, Giardia, Leishmania, Naegleria, Plasmodium, Trichomonas, and Trypanosoma and their medical and taxonomical consequences. Proc. Natl. Acad. Sci. USA 87: 2414-2418.

72. Tibayrenc, M.; Ward, P.; Moya, A.; Ayala, F.J. (1986). Natural populations of Trypanosoma cruzi, the agent of Chagas disease, have a complex multiclonal structure. Proc. Natl. Acad. Sci. USA 83: 115-119.

73. Whelan, W.L.; Kirsch, D.R.; Kwon-Chung, K.J.; Wahl, S.M.; Smith, P.D. (1990). Candida albicans in patients with the acquired immunodeficiency syndrome: absence of a novel of hypervirulent strain. J. Inf. Dis. 162: 513-518.

74. Xu, J.; Mitchell, T.G.; Vilgalys, R. (1999). PCR-restriction fragment length polymorphism (RFLP) analyses reveal both extensive clonality and local genetic differences in Candida albicans. Mol. Ecol. 8: 59-73.

75. Xu, J.; Vilgalys, R.; Mitchell, T.G. (1999). Lack of genetic differentiation between two geographically diverse samples of Candida albicans isolated from patients infected with human immunodeficiency virus. J. Bacteriol. 181: 1369-1373. 